the preventive aspect of medicine there. At Shell Haven routine chest films are taken of all who join the company and all who go overseas and in addition of tetraethyl lead handlers, chemical product handlers, chemical plumbers, benzene workers, alkylate workers, and tank cleaners. In the laboratory full blood counts are performed at six-monthly intervals on tetraethyl lead workers, benzene workers, chemical product handlers, chemical plumbers (on whom stipple counts are also done), tank cleaners, and industrial radiographers. Routine urine examinations are also performed on all these groups of workers, and as new processes are developed the medical officer joins the consultations with the planners so that new hazards may be anticipated and, if necessary, new laboratory control be instituted in those workers exposed to new and perhaps unpredictable hazards to health.

Certain auxiliary services also find a place in the medical centre : these are physiotherapy, an ophthalmological service, and a dental service. Each specialty has its own set of rooms, and, under the N.H.S., an ophthalmologist, a dentist, and an optician visit the Centre to treat and prescribe. Simple forms of physiotherapy are carried out by the Centre's own staff, and their rooms can also be used as rest-rooms. The specialist services in particular cut down the number of wasted man-hours in which workers would otherwise have to go to, receive treatment, and return to work from any of the neighbouring hospitals or surgeries. In the same way the time of general practitioners is also saved by carrying out their routine treatments at the Centre instead of at individual surgeries. These practices have, as well as their obvious functions, the important one of making the Centre a close ally of the local general practitioners and consultants. It takes its place in the pattern of preventive medicine and of potential research not only in a selected group but of the whole community in its relation to several environments.

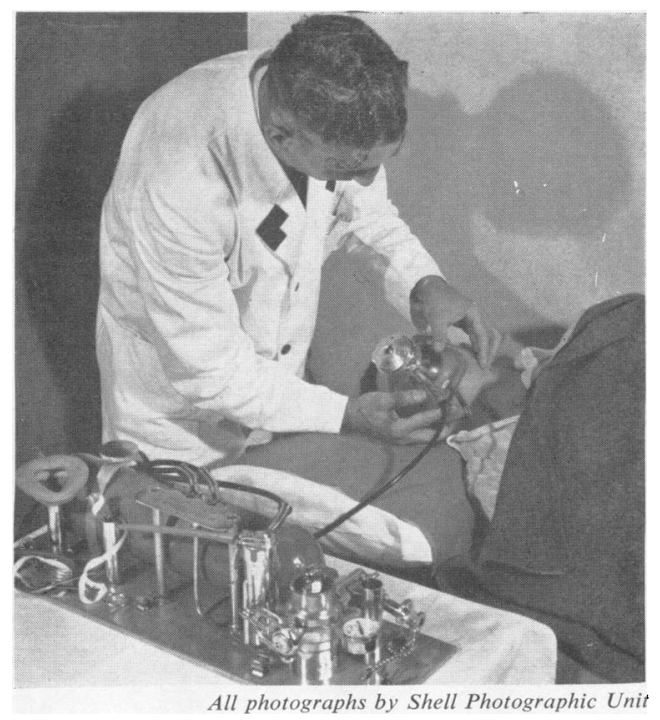

\section{British Occupational Hygiene} Society

\section{The Use and Abuse of Protective Equipment}

\section{N. DAVIES}

This conference was held in London on November 4, 1955. It was divided into four sections dealing respectively with the protection of the lungs, skin, eyes, and feet.

The morning session was opened by Mr. S. H. Wilkes, Senior Chemical Inspector of Factories, who gave a warning that the canister respirator, which was an excellent device in its own proper field, should not be used inside closed spaces where there might be high concentrations of poisonous substances or a shortage of air. An air line respirator fed with fresh air from a hand pump should always be used in such situations.

Papers on the protection of the lungs were presented by Mr. A. C. Peacock, of the Chemical Defence Experimental Establishment, Porton, and by Mr. J. Whittaker, of the Central Safety Department, Imperial Chemical Industries, Ltd.

Mr. Peacock stated that protection of a worker by means of a respirator must be regarded as a second-best substitute for tackling the hazard at its source.

The design of a respirator had to be considered as a whole ; vision, comfort, and speech had to be ensured and must be combined with durability and low breathing resistance. It was also important that the hazard against which it was to be used should be fully specified so that the most appropriate kinds of filter could be incorporated.

Gases and vapours were absorbed by activated charcoal which was usually suitable unless the molecular weight was too low. It was then necessary to impregnate with catalysts. Ammonia, oxides of carbon, and the oxides of nitrogen needed special absorbents. Aerosols were taken out by fibrous filters in the form of paper, carded lap, or felted fabric.

The fit of the facepiece was important as contact with the skin without the use of excessive pressure had to be maintained when the head was moved violently. It was easier to fit well full-size face masks going under the chin than small ones covering only the mouth and nose. It had been established that a plain polished surface gave better contact with dry skin than a roughened one.

The larger the protective appliance, however, the greater was the aversion of the worker to wearing it and the greater the risk of its being discarded. Workers in the older industries were difficult to discipline in this matter and propaganda based on fear or a humorous appeal was deprecated. The atomic energy industry was exceptional and fcrtunate in that its employees were well aware of the danger of their working conditions and cooperated fully in the precautions advised.

Mr. Whittaker emphasized that the prevention of lung injuries began with good design of buildings, processes, and plant, followed by the use of sound operational methods and the training and control of personnel. Personal protective equipment was a last resort, required by law in certain operations. 
The discussion on protection of the lungs was opened by the President of the Society, Dr. J. M. Rogan, Chief Medical Officer of the National Coal Board. He mentioned one difficulty when canisters were used in protective masks. This was the lack of any visible indicator of the amount of useful life left in them, which depended not only upon the concentrations of gas in which they had been used but also upon the rate of breathing.

In assessing the danger of a dust it had to be remembered that the intratracheal toxicity was usually many times greater than the oral figure.

The cooperative attitude to protective measures of workers in atomic energy establishments was put down to their being accustomed from the start to hazards outside human perception, to their being given full information about the risks, and to good discipline.

The second section of the conference, on the protection of the skin, consisted of papers by Professor J. R. Squire of the Department of Experimental Pathology, University of Birmingham, and Dr. A. Lloyd Potter, of the General Chemicals Division of Imperial Chemical Industries Ltd.

Professor Squire gave an account of the structure of human skin and explained the mechanisms of various kinds of damage. The outer layer of the epidermis was chemically inert and resistant to acids but it swelled in alkalis and, being a protein, could react with, absorb, and transmit substances which contained $-\mathrm{NH}_{2}$ or -SH groups. It was also liable to be destroyed by reducing agents and cracked if dried excessively. Normally loss of water was impeded by the fatty surface film so that removal of this by solvents might result in " chapping ". The fatty layer was replenished in about two hours.

Sheer mechanical abrasion was encountered in some occupations. The horny surface of the skin was constantly replaced from the germinal layer, and if the rate of abrasion was too high and gloves could not be worn, a shorter shift was the only remedy.

Chemical agents acting as irritants produced their effect in 48 hcurs or less, but sensitizing chemicals inight produce intense reaction on a second exposure 10 or 14 days after the initial one. Once sensitized to a specific chemical a man could react to minute traces of it. Complete removal to another occupation was necessary in these cases. Carcinogens required years to produce even the pre-cancerous effects and the peak incidence of the cancers was 20 to 30 years after exposure; their action was dependent on repeated exposure and could be reduced by lessening the amount of carcinogen reaching the skin.

Mechanical handling avoided many risks but was not applied to many jobs of low economic value ; for such occupations personal protection was necessary. The organization of protective equipment should include provision for inspection, repair, and cleaning. There was a risk of transferring contamination to the person when soiled clothing was removed. Barrier creams could be relied on to exclude a toxic chemical only in exceptional instances.

Dr. Lloyd Potter stated that although occupational dermatitis was not notifiable to the Chief Inspector of
Factories over 3,000 cases were voluntarily reported each year. In order to affect the skin a substance must wet it, either by being itself in liquid form or by solution in perspiration or other liquid on the surface of the skin. Water, alcohol, and weak acids did not greatly affect the cells of the skin, but they were easily damaged by alkalis and fat solvents which penetrated the natural greasy barrier and reached the sebaceous layer. Dermatitic agents fell into two groups : primary irritants and skin sensitizers. It was almost impossible for the employee who was liable to contract dermatitis to be detected before employment by medical examination, but regular examination subsequently was very important.

The ideal method of protection was by completely enclosing a process, but this could be nullified if, for example, the final product was packed by hand. Protective clothing should be neat and effective; it should not add to the risk of contracting dermatitis by causing sweating and chafing. Inspection, laundering, and repair should be organized and the wearer should be educated by precept and example. Proper washing facilities were important and barrier creams had their place if only because they encouraged washing.

In the discussion Professor Squire stated that the $p \mathrm{H}$ of the skin was about 4.5 or 4.6 , partly due to carbon dioxide transpiration and partly to free fatty acid in the surface film. The fatty acid layer gave important protection and might be disturbed by long exposure to alkalis.

Introducing the speakers in the afternoon session of the Conference, Sir Harold Roberts, Chief Inspector of Mines, stated that mining was the most dangerous of all major industries. The death rate in coal-mining was nine times as high as the death rate in factories. The absolute figures were improving but relative to employment in factories there seemed to be little change. Major catastrophes were responsible for only a very small proportion of the casualties in mines; the major toll was taken by falls of roof and transport operations.

Injuries to the feet and ankles were common and the wearing of safety boots bearing the British Standard mark was encouraged, but there was a long way to go before they were universally adopted by all workers. It was even more difficult to get the underground worker to wear goggles. Even the slightest interference with vision was trying and could create additional risks. Improvement in lighting had, however, made a real contribution to safety and to the prevention of miner's nystagmus.

The President stated that the fatal accident rate in British mines was half the German rate, one-third of the American, and lower than that of any other mining country except the Netherlands.

Dr. D. R. Campbell, Director of Research, Birmingham and Midland Eye Hospital, read a paper on "Ocular Injuries and Hazards". She stated that eye injuries constituted $4 \cdot 26 \%$ of all industrial accidents ; most of them were due to flying particles and were often preventable. In addition, there were thousands of minor injuries from the same cause which were not reported because they caused less than three days' absence from 
work. The risk was greatest in metal foundries and heavy engineering.

In the matter of protection, it was disheartening to find so many goggles which steamed up, restricted vision, and were uncomfortable to wear. The issue" of goggles to every individual worker, each being given a choice of four designs, in a large engineering factory had demonstrated that a great decrease in accidents could be achieved.

Ocular injuries could often be repaired now that the complication of infection was largely absent; all the same, even a small scar in the centre of the cornea could cause disability by dazzle in artificial light. Eye protection should be compulsory in occupations involving striking and chipping with a metal tool. Burns from molten metal and chemicals, especially caustic soda, were dangerous. Immediate irrigation with water might be the means of saving the eye.

In his paper on "Eye Protection, Types of Equipment and their Use", Mr. G. V. Thom, Plastics Division Safety Officer, Imperial Chemical Industries Ltd., explained the legal obligations to provide protection for the eyes against certain hazards which are laid down by the Factories Acts and are required by Common Law.

Built-in protection upon the machine, rather than upon its operator, was desirable, and he showed illustrations of typical methods of applying this principle.

Personal eye protection included spectacles, which could have prescription lenses made in safety glass, eye shields covering a part or all of the face, and goggles. Protection against infra-red rays was needed in welding and against ultra-violet as well in electric arc welding, which necessitated screening the whole of the face. British Standards for protective appliances were in existence. Persons with monocular vision should be given special attention because of the risk of total blindness, particularly because the existence of their disability might be unsuspected at the works.

It was suggested in the discussion that old hammers and chisels with mushroomed heads were a common source of intraocular foreign bodies; the risk was decreased by regular replacement of worn tools. Limitation of the field of vision by goggles, especially downwards, and interference with binocular vision discouraged their use. Other points raised were the need for safety glass, plastics which were not inflammable, and the fact that coloured glass which gave protection against radiation from flame welding might be useless for arc welding.

Mr. H. Bradley, Director of the British Boot and Shoe and Allied Trades Research Association, spoke first on the protection of the feet and was followed by Mr. H. E. Thomas, Head of the Safety Department of the Ford Motor Company, Dagenham. Mr. Bradley outlined the steps which had led to the drafting of a British Standard for safety footwear. These have a steel toe-cap which has to resist an impact test. In the experience of $\mathrm{Mr}$. Thomas the standard safety boot or shoe did, in some instances, give protection, but there were still many cases of toe fracture while wearing them. He suggested that the metal toe box be extended further back, even though this meant it would be unable to pass the impact test.

\section{ORDINARY SCIENTIFIC MEETING}

An ordinary scientific meeting of the British Occupational Hygiene Society was held at the London School of Hygiene and Tropical Medicine on June 20. Dr. T. Bedford was in the chair and some 50 members were present. A brief summary of the papers contributed to this meeting is given below.

\section{Exposure to Trichloroethylene during an Industrial Degreasing Operation}

D. E. Hickish, J. H. Smith, and Joan Bedford reported the results of a routine examination of a typical degreasing operation using a toxic solvent. The methods of collection and subsequent analysis of air samples were discussed. Urine specimens and blood samples were examined and clinical examinations performed. Concentrations of the solvent in air in excess of those recommended as the maximum allowable were discovered. Some abnormalities in the blood and urine specimens and mild clinical symptoms were noted. There were, however, no major pathological disorders.

The need for routine supervision of potentially dangerous operations was emphasized.

\section{Procedures relating to the Safety and Hygiene of Persons Handling Tetraethyl Lead in the U.K. and Overseas}

P. R. Boyd outlined the tetraethyl lead hazard with reference to the areas and spheres of activity in which this compound is handled. The general administration and supervision of those exposed to the potential absorption of this material were discussed in relation both to the manufacturers and to the customers and users.

The detailed control in terms of plant hygiene and human monitoring was briefly described, showing the combined use of clinical supervision and of analysis of human excreta and of the atmospheric environment.

The tetraethyl lead industry is a good example of one involving severe occupational hazards which can be controlled by detailed supervision.

\section{A Small Outbreak of Mercurialism in Laboratory Workers}

J. F. Erskine described a small outbreak of mercury poisoning in laboratory workers analysing mine air samples. Symptoms were minimal but the probable cause was confirmed by the finding of mercury in the urine. The risk was partly eliminated by cleaning the laboratory and improving the working conditions. It was finally eliminated by a change in the method of analysis so that open vessels of mercury were no longer required.

The outbreak demonstrated the risk of chemical poisoning to laboratory workers when, by increasing demand, ordinary laboratory techniques are converted to mass production methods, and the fact that the risk can be eliminated by the normally accepted methods of plant hygiene. 